\title{
Linearly variable chord-extension morphing for helicopter rotor blades
}

\author{
Rohin K. Majeti ${ }^{1}$ (1) $\cdot$ Berend G. van der Wall ${ }^{1}$ Christoph G. Balzarek ${ }^{2}$
}

Received: 26 June 2019 / Revised: 28 August 2020 / Accepted: 25 September 2020 / Published online: 15 October 2020

(c) The Author(s) 2020

\begin{abstract}
A new morphing concept called linearly variable chord extension was studied for its effectiveness in improving the efficiency of a helicopter rotor. Apart from chord extension itself, an additional feature which is deflection of the extended part of the chord resulting in an effective camber and additional twist to the airfoil, is also studied for its effect on rotor efficiency improvement. Trim analyses were carried out for various chord-extended rotors for hover as well as various forward flight velocities using DLR's in-house comprehensive analysis code S4. Chord extension of up to 100\% and chord-extension-deflection of up to $15^{\circ}$ were considered. Results show that the linearly variable chord-extension concept is effective in reducing power requirement in both hover and forward flight. Deflection of the extended chord also helps reduce power requirement in hover, especially at higher blade loadings. However, the root torsional moments and hence, the pitch-link loads are seen to increase substantially for the morphed rotors.
\end{abstract}

Keywords SABRE $\cdot$ Rotor blade morphing $\cdot$ Helicopter rotor efficiency $\cdot$ Variable chord extension morphing

$\begin{array}{ll}\text { List of symbols } \\ \mathrm{BL} & \text { Baseline } \\ \mathrm{cg} & \text { Center of gravity } \\ \mathrm{FM} & \text { Rotor figure of merit } \\ c & \text { Rotor blade chord length, } \mathrm{m} \\ C_{\mathrm{m}} & \text { Airfoil moment coefficient } \\ C_{\mathrm{n}} & \text { Airfoil normal force coefficient } \\ C_{x} & \text { Airfoil chord force coefficient } \\ C_{\mathrm{P}} & \text { Rotor power coefficient } \\ C_{\mathrm{T}} & \text { Rotor thrust coefficient } \\ \mathrm{EI}_{\eta}, & \text { Flap stiffness, Nm }{ }^{2} \\ \mathrm{EI}_{\zeta} & \text { Lag stiffness, Nm }{ }^{2} \\ f & \text { Rotor natural frequency, Hz } \\ F_{\mathrm{PL}} & \text { Pitch-link load, N } \\ \mathrm{GJ} & \text { Torsional stiffness, Nm } \\ M_{x} & \text { Component of Mach number along the chord line } \\ M_{z} & \text { Component of Mach number normal to chord line } \\ P & \text { Required rotor power, } \mathrm{kW} \\ r & \text { Rotor blade radius variable, } \mathrm{m}\end{array}$

Rohin K. Majeti

rohin.majeti@dlr.de

1 Institute of Flight Systems, German Aerospace Center (DLR), Brunswick, Germany

2 Institute of Composite Structures and Adaptive Systems, German Aerospace Center (DLR), Brunswick, Germany $\bar{r} \quad$ Non-dimensional rotor radius variable

$r_{\text {hinge }} \quad$ Radial location of chord-extension hinge, $\mathrm{m}$

$r_{\theta} \quad$ Polar radius of gyration, $\mathrm{m}$

$R \quad$ Radius of rotor, $\mathrm{m}$

$X_{\mathrm{CG}} \quad$ Chordwise location, center of gravity of Airfoil, $\mathrm{m}$

$X_{\mathrm{SC}} \quad$ Chordwise location, shear center of Airfoil, $\mathrm{m}$

$\alpha \quad$ Angle of attack, ${ }^{\circ}$

$\lambda \quad$ Non-dimensional inflow

$\mu \quad$ Advance ratio

$\sigma \quad$ Rotor solidity

$\theta_{0} \quad$ Rotor collective angle, ${ }^{\circ}$

$\omega \quad$ Rotor natural frequency, $\mathrm{rad} / \mathrm{s}$

$\Omega \quad$ Rotor rotational speed, $\mathrm{rad} / \mathrm{s}$

$\Omega_{\text {ref }}$ Reference rotor rotational speed, $44.4 \mathrm{rad} / \mathrm{s}$

\section{Introduction}

The main rotor is the most important sub-component in helicopters, because it provides lift, propulsion and control. It is designed to operate in different flight regimes under complex aerodynamic conditions. It is a challenge to design the rotor to operate efficiently in all flight regimes from hover to fast forward flight and high-g maneuvers while at the same time, maintaining its vibration, stability, stress and safety limits. This has resulted in design compromises in the form of a 
fixed geometry. Since optimal values of rotor geometrical parameters vary for different flight regimes, a morphing rotor capable of changing its geometry during flight will allow overcoming of such compromises.

Various morphing concepts have been researched, recently, for performance improvement, vibration and noise reduction. In Ref. [1], several morphing concepts including variable blade radius, variable blade chord length and variable rotor angular speed were examined for their role in improving helicopter performance in cruise and in increasing the maximum speed and maximum load capability. It was found that for rotor performance in cruise, the variable blade chord length was a very effective morphing parameter. In Refs. [2,3], it was shown that chord extension morphing over a spanwise section can reduce main rotor power requirements in stall-dominant flight conditions while being able to increase the maximum gross weight, altitude, and flight speed capability of the aircraft. In addition to static chord extension, dynamic chord extension (1/rev) was also found to be effective for performance improvement and increasing load capability $[1,4]$.

Several rotor morphing concepts are being developed, analyzed and tested within the European research program SABRE [5] with the primary objective of optimizing helicopter emissions reduction. SABRE has a tightly crosslinked, dual stream research methodology with emissionfocused rotor performance analysis running concurrently with morphing technology development. Within SABRE, DLR Germany is responsible for analyzing and developing the variable chord extension concept. The comprehensive analysis of isolated rotor is being carried out at the Institute of Flight Systems, while the structural design and actuation concept is being developed and tested at the Institute of Composite Structures and Adaptive Systems. This paper presents the results and progress made in achieving the objective of this morphing concept. The Bo105 main rotor blade with the airfoil NACA23012tab was selected as the baseline blade.

\section{Linearly variable chord-extension concept}

In literature, the chord-extension concept mostly meant sliding a discrete chord-extension plate out of a part of the trailing edge. This approach leads to a discontinuous blade surface and results in significant drag penalty. It is known that for each section of a rotor blade to operate at the optimum lift-to-drag ratio, the so-called "optimum hovering rotor", the blade chord must vary hyperbolically with span [6]. The variable chord-extension scheme comes close to representing this geometry. Here, a part of the blade is hinged out on the leading edge and trailing edge sides to provide a linear increase of the chord length from the hinge to the blade root.
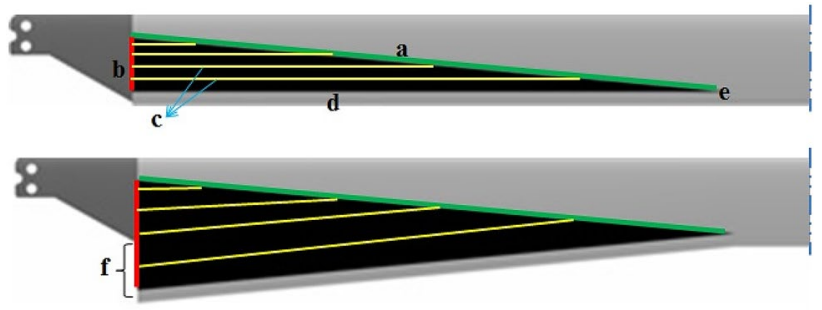

Fig. 1 Unmorphed rotor blade (top) and the fully extended rotor blade with a- auxiliary spar (green), b- guidance system (red), c- web stiffeners, $\mathbf{d}$ - rear spar, e- hinge, $\mathbf{f}$ - maximum chord extension

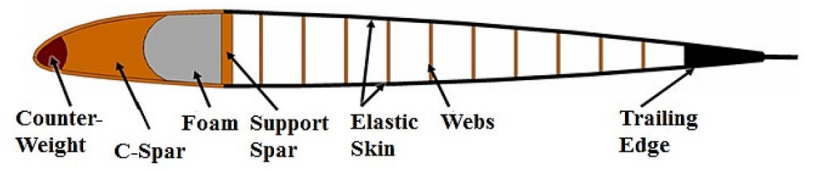

Fig. 2 Blade cross section

However, chord extension on the leading edge is much more difficult to achieve practically and hence was not considered in this study. Instead, only the trailing edge is hinged out, as shown in Fig. 1. In addition to the chord extension, another feature was also investigated. This involved deflecting the extended chord in a similar manner as would be done with a trailing-edge flap, thereby introducing significant amount of camber and modifying the overall twist. The chord extension and its' deflection are expected to vary with flight velocity.

\subsection{Structural concept}

The structural concept for the linearly variable chord-extension morphing is described as follows referring to Fig. 1. A rear spar $(d)$ is located in the trailing edge and can be swept back around a pivot point $(e)$ which is located at a desired blade radius. At the innermost radial location of the aerodynamic section (at $22 \%$ blade radius) this spar is actuated perpendicular to the radial direction by an actuator. It is to be noted that the term 'maximum chord extension' refers to the chord extension at this location. In the morphed region, the blade section consists of a conventional front structure made of a C-spar, a counterweight and a load bearing composite skin (Fig. 2). This conventional region ends at a diagonally implemented auxiliary spar (green line). In the morphing rear part, an elastic skin is used, which allows the morphing to take place. Unidirectional reinforcements in the radial direction account for the centrifugal loads on the skin. To maintain the airfoil shape of the soft skin, a number of support elements $(c)$ are used. They keep the distance between the upper and lower skin and transfer aerodynamic loads from the skin into the auxiliary spar and a support at the 
root. The trailing edge rear spar is a stiff component which transfers the actuator force applied at the blade root and transmits the deflection all the way up to the pivot point. For extending the chord, the sub-structure in the rear part of the blade is expanded and the elastic skin is stretched. This approach gives a smoother and a continuous blade surface, significantly reducing the drag penalty as compared to a discrete chord-extension concept.

The design of the rotor blade is an iterative process. Objectives of the design process include limiting skin/ web local deflections due to the surrounding air pressure environment, limiting the center of gravity offset from the shear center and redistributing blade stiffness distributions to avoid resonant conditions at design rotor speed. An automated optimization routine has been developed that includes several sensitivity studies performing FE-based calculations. The goal of the optimization is primarily the shape accuracy of the airfoils and the associated performance preservation compared to a rigid blade structure. Important parameters for the optimization included the variation of the materials, the layer structure of the individual components as well as the geometry of the sub-structure.

\subsection{Airfoil aerodynamics}

The baseline airfoil along with the chord extension and deflection features is shown in Fig. 3. Since chord extension and deflection change the baseline NACA23012tab airfoil shape, Navier-Stokes based computational fluid dynamics (CFD) was used to calculate the two-dimensional aerodynamic coefficients of the modified airfoil over a range of angles of attack, $\alpha$, up to twice the stall angle for various Mach numbers, $M$, including reverse flow. Based on the newly computed CFD data, an analytical model of the airfoil coefficients was synthesized for ease-of-use within the comprehensive analysis. The analytical model is based on the unsteady aerodynamic formulation proposed by Leiss with a few modifications and includes dynamic stall [7, 8]. This model works with airfoil coefficients normal and tangential to the chord line (airfoil coordinate system) in contrast to the classical coefficients which are defined in the

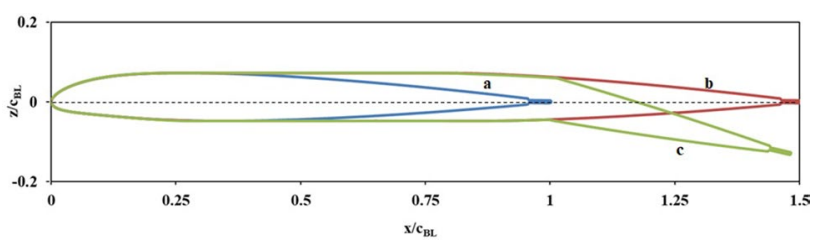

Fig. 3 NACA23012tab airfoil with chord extension and deflection. a- Baseline airfoil, b- with 50\% chord extension, c- with 50\% chord extension and deflection

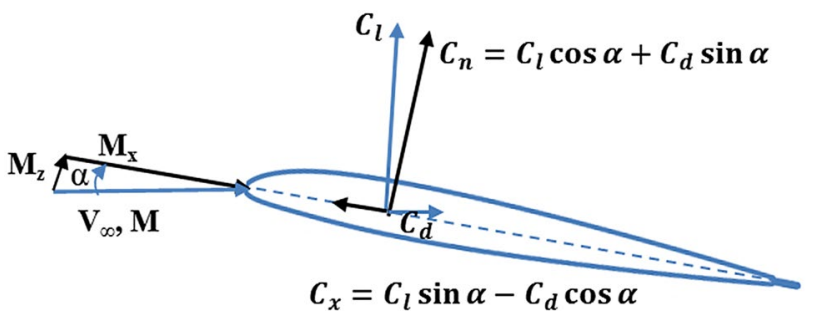

Fig. 4 Transformation of aerodynamic coefficients to the airfoil coordinate system

aerodynamic coordinate system. The relationship between the airfoil coefficients and the aerodynamic coefficients are shown in Fig. 4. Calculation of the airfoil coefficients in the Leiss model are based on the Mach components in the airfoil coordinate system rather than on $\alpha$ and $\mathrm{M}$. The parameters of the Leiss model are estimated for the baseline airfoil and for the chord-extended geometries with and without deflection. The difference in parameter values between the morphed and baseline airfoil geometries (delta functions) are then modelled as polynomial functions of the morphing parameters and Mach number. These delta functions together with the analytical model of the baseline airfoil coefficients form the complete model for the morphed airfoil. Thus, a complete nonlinear, unsteady analytical model for the airfoil coefficients as a continuous function of morphing parameters and Mach number and including dynamic stall, yawed flow etc. was synthesized.

CFD polars were computed for baseline and morphed airfoils pitching in a quasi-steady manner at various Mach numbers. For the morphed airfoil cases, $25 \%, 50 \%$ and $75 \%$ maximum chord-extension were selected for $M=0.2$ (reverse flow), 0.2 and 0.4. This is because the chord extension is applied only to the inner half of the rotor blade. Reverse flow indicates flow from trailing edge towards leading edge. The inner-half of the rotor blade experiences a maximum $M \approx 0.5$ and also some reverse flow near the root in the retreating blade during forward flight.

Figure 5 shows the airfoil coefficients from CFD computations for a sample case of rotor blade with $75 \%$ chord extension at deflections of $0^{\circ}, 7.5^{\circ}$, and $15^{\circ}$ for Mach number $M=0.2$. The baseline blade polars are also plotted for comparison. The airfoil coefficients are plotted against the vertical component of the Mach number which is representative of the angle of attack. Large, random fluctuations in the airfoil polars are seen beyond the stall region. These fluctuations are mainly observed in the vicinity of $M=0.2$ and are less for higher Mach numbers. This scatter in the CFD results is nonphysical and is the result of the large time step used. In these regions, the mean value can be considered to be representative of the airfoil coefficient. A slight hysteresis near stall is also observed which is ignored in the analytical 


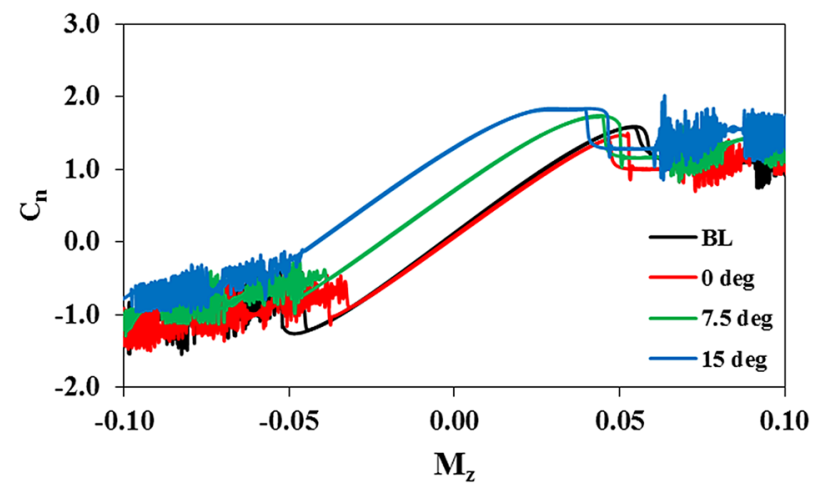

(a) Normal force coefficient

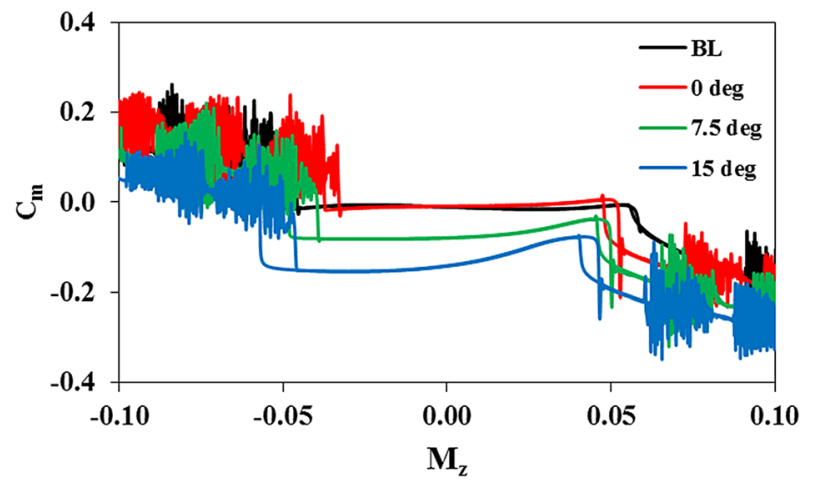

(b) Moment coefficient

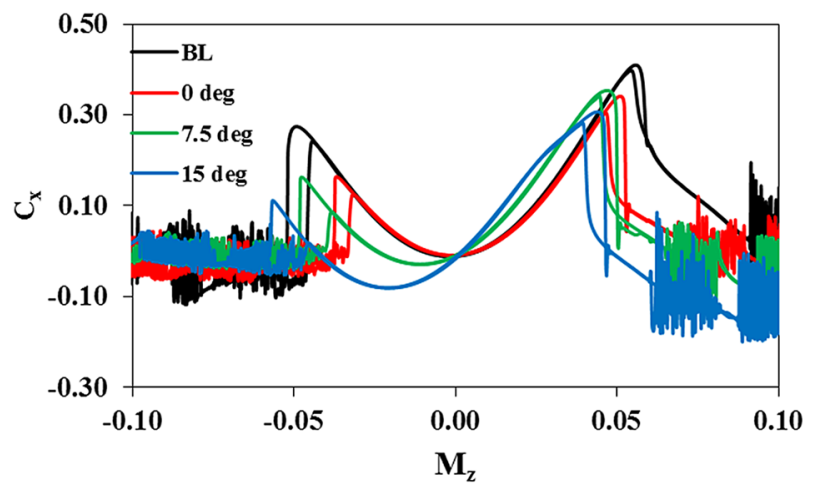

(c) Chord force coefficient

Fig. 5 Airfoil coefficients for $75 \%$ chord extension at Mach number, $\mathrm{M}=0.2$

model. A reduction in the stall angle is observed for the chord-extended airfoil compared to the baseline airfoil. While it is not shown here, in fact, this reduction is observed to be proportionate with chord extension. This trend is representative of the flow at other Mach numbers too and can be attributed to the fact that the chord-extended airfoils are now thinner than the baseline airfoil in relation to their longer chord. Another observation from the figure is that the lift and nose-down moment increase with increase in chord deflection. This is because the chord deflection increases the camber of the airfoil. A slight increase in drag is also observed with increase in chord deflection. The synthesized analytical model was extrapolated for chord extensions up to $100 \%$ and Mach numbers up to $M=0.6$. Good correlation was found with the CFD data.

\subsection{Comprehensive analysis}

The analysis of the isolated rotor for hover and forward flight conditions is performed using DLR's comprehensive analysis tool $\mathrm{S} 4$, which is a high resolution, nonlinear, unsteady aerodynamics code with elastic blade structural model. For structural dynamics of the rotor, first, modal analysis is performed using finite element method (FEM) based on the Houbolt-Brooks formulation [9] which considers flap, lag and torsion degrees for the blade element. Next, for the dynamic response problem, the blade modes are subjected to generalized aerodynamic forces and generalized coupling forces from other modes like flap-torsion and flap-lag. The response problem is then solved using Runge-Kutta fourth order time-integration method until convergence is achieved. The code also includes an isolated rotor trim module, where the algorithm adjusts the collective pitch and cyclic pitch control inputs and the rotor shaft angle (for forward flight cases) until a trim goal is met.

For aerodynamic calculations, the rotor blade was discretized into 20 elements as per constant ring area criteria with smaller element width near the tip to capture tip-loss effects. The aerodynamic properties are evaluated at collocation points within each element. A tip-loss correction factor has been included, wherein the sectional inflow is modified so that the sectional lift gradually goes to zero at the tip. For current calculations, tip loss has been taken to be effective from $0.9 \mathrm{R}$ and has been assumed to be constant with thrust. Chord extension is given near the root with linear variation from a hinge at mid-span till the root cutout. Figure 6 shows a schematic of the baseline rotor and a representative $75 \%$ chord extension near the root. The chord-extension hinge, in this case, is located at $0.5 R$. The Mangler and Squire inflow model [10] was chosen for the current analysis. This is a global inflow model using the incompressible, linearized, Euler equations to relate the pressure field across the disk to

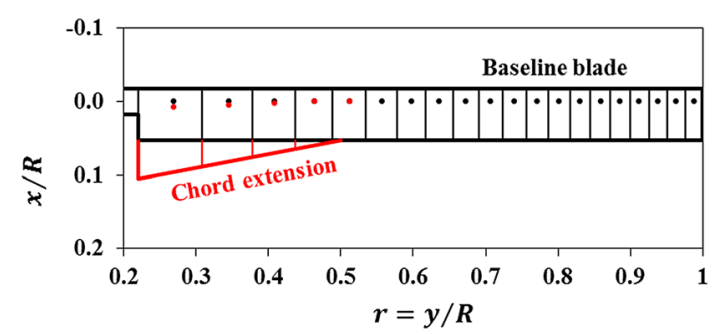

Fig. 6 Baseline and chord-extended rotor blade discretization 
the inflow. The resulting inflow, $\lambda$, can be described by the Fourier series:

$\lambda=\left(\frac{2 C_{\mathrm{T}}}{\mu}\right)\left[\frac{c_{0}}{2}+\sum_{n=1}^{\infty}\left((-1)^{n} c_{n}(\bar{r}, \alpha) \cos n \psi\right)\right]$,

where $\alpha$ is the disk angle of attack, $\psi$ is the azimuth angle and $\mathrm{c}_{\mathrm{n}}$ are constants that depend on the rotor loading. A fuselage-rotor inflow interference model was also included in the analysis. The interference from the fuselage modifies the inflow in the front and rear part of the rotor disk in the inboard regions and reduces the overall power requirements.

In the current work, surrogate models were created with maximum chord extension and chord-extension-deflection as variables. Maximum chord extensions of 0\%, 25\%, 50\%, 75\% and $100 \%$ of baseline chord length and with deflections of $0^{\circ}$, $5^{\circ}, 10^{\circ}$ and $15^{\circ}$ were considered. The combination of these variables resulted in 17 different cases. These 17 different rotor cases were trimmed in hover and forward flight conditions and compared with the baseline rotor case for power requirement.

\section{Results}

\subsection{Effect of chord-extension hinge position}

First, a short study was carried out on the effect of varying the hinge position on the figure of merit in hover. Figure of merit (FM) is used as a measure of performance for a hovering rotor and is defined as the ratio of ideal power to the actual power required for hover. From Momentum theory,

$C_{\text {P,ideal }}=C_{\mathrm{T}} \lambda_{i, \text { ideal }}=\sqrt{\frac{C_{\mathrm{T}}^{3}}{2}}$,

$\mathrm{FM}=\frac{C_{\mathrm{P}, \text { ideal }}}{C_{\mathrm{P}}}$.

Fig. 7 Effect of chord-extension hinge position on hover performance
For a maximum chord extension of $75 \%$ baseline chord, the chord-extension hinge location was varied from $0.4 R$ to $0.6 R$, where $\mathrm{R}$ is the radius of the blade. Figure 7 shows the effect of hinge location on FM (Fig. 7a) and power gain (Fig. 7b) with respect to the baseline blade. The FM is seen to increase with increase in the hinge radius for all blade loadings. There is a maximum gain of 7 counts in FM at the nominal blade solidity of 0.071 for the case of hinge location at $0.6 R$ compared to the baseline blade. There is a gain in power for the chord-extended rotors over the baseline blade with a maximum of $9 \%$ for the case of hinge at $0.6 R$ at nominal blade solidity. Quite clearly, the hinge location at $0.6 R$ results in a higher FM and lower power requirements as compared to the baseline blade whether at lower thrust or higher thrust. The reason for reduced power requirements in chord-extended rotor is the overall reduction in the angles of attack observed over the blade relative to those in the baseline blade and to the better lift-to-drag ratio of the chordextended rotor. This shall be analyzed in more detail later.

\subsection{Structural dynamics}

Choosing $0.6 R$ as the hinge location, the structural configuration of the morphed rotor was iterated till its dynamic properties, as represented by its Campbell diagram, ensured resonant-free conditions at the design rotor speed. The baseline blade structural configuration data is available in the open literature [11]. In this report, only the most significant and modified rotor blade properties resulting from the iterative design process are shown. It is to be noted that the titanium rotor hub and the blade attachment up to the main bolt are very stiff compared to the rest of the blade. The $0 \%$ chord-extension rotor is aerodynamically the same as the baseline Bo105 rotor; however, because of the additional spars and stiffeners and the elastic skin, its mass and stiffness distributions are modified in the morphed region. The hard foam filler in the baseline blade was replaced by light web stiffeners and the glass fiber fabric skin on the chordwise rear part of the blade was replaced by lightweight elastic

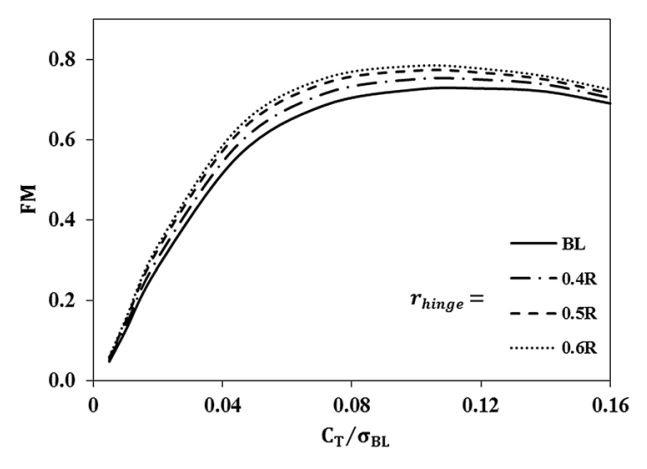

(a) Figure of merit (FM)

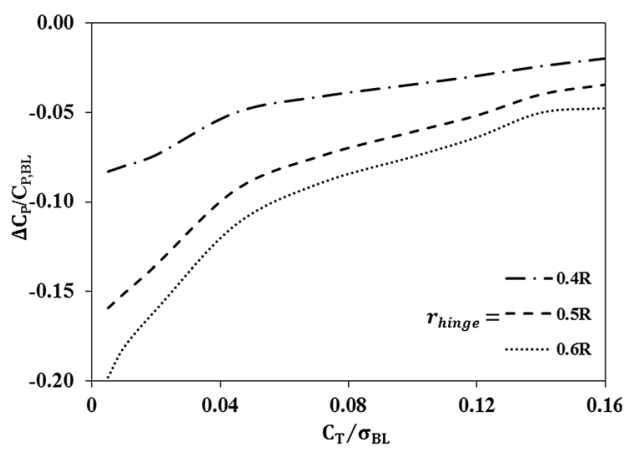

(b) Power gain wrt baseline blade 
Fig. 8 Structural data distribution of the baseline and chordextended rotor blades

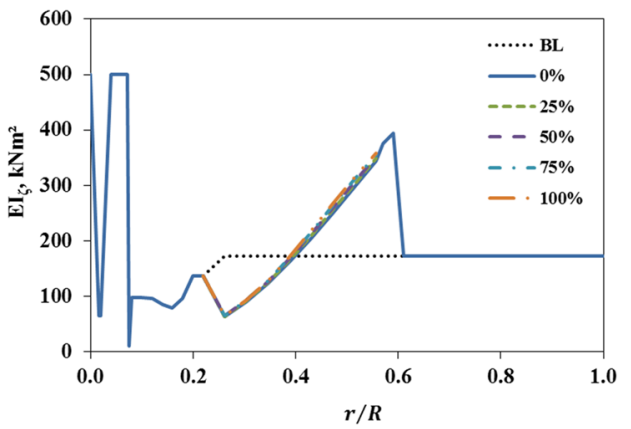

(a) Lag stiffness radial distribution

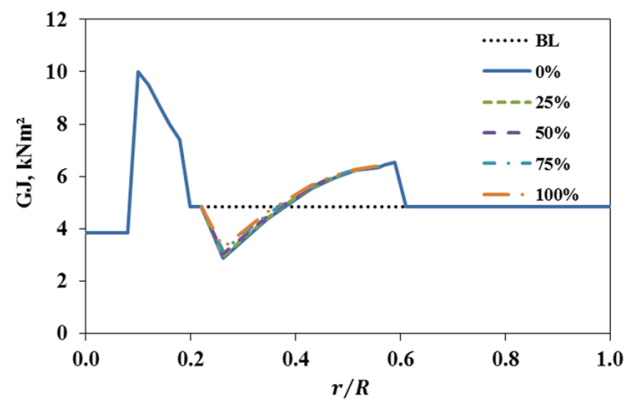

(b)Torsion stiffness radial distribution
Fig. 9 Shear center $\left(X_{\mathrm{sc}}\right)$, center of gravity $\left(X_{\mathrm{cg}}\right)$ radial variation as a ratio of the baseline chord

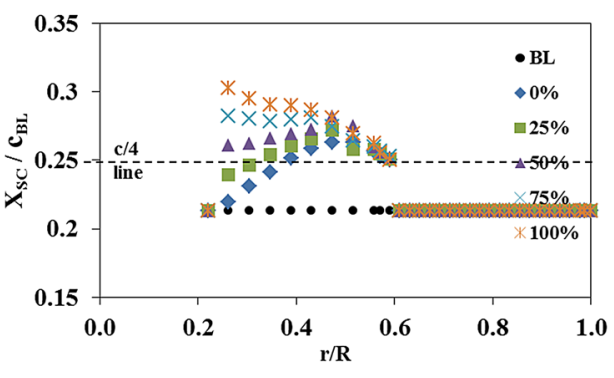

(a) Shear center

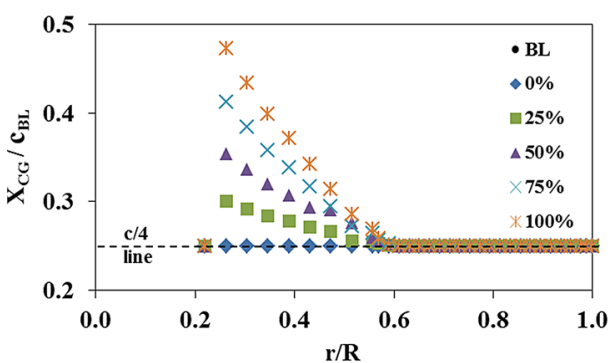

(b) Center of gravity skin. Hence, the mass density m' and flap stiffness distribution $\mathrm{EI}_{\eta}$ do not vary much for the $0 \%$ chord-extension blade from those of the baseline blade. Extending the chord modifies these properties only marginally and hence, these properties are not shown here. However, the lag bending stiffness $\mathrm{EI}_{\zeta}$ and the torsional stiffness GJ are modified in the morphed region for the $0 \%$ chord-extension rotor and these properties are shown in Fig. 8 for the baseline and chordextended rotors. $\mathrm{EI}_{\zeta}$ and $\mathrm{GJ}$ have been redistributed with reduction in some parts and increase in others resulting in a small change in the overall values over the morphed region. There is a slight variation of these stiffnesses as the chord is extended from 0 to $100 \%$. Figure 9 shows locations of the shear center (a) and the center of gravity (b) with respect to the leading edge in terms of the baseline chord length. The variations of these properties along the radius for different maximum chord-extension cases are given here. For the baseline blade, the shear center is ahead of the quarterchord line and the cg coincides with the quarter-chord line. For the chord-extended cases, the shear center and the cg are farther from the leading edge in the inboard sections because of the shift of mass farther away from the leading edge. As the chord extension reduces linearly to zero towards the hinge, these values get closer to the quarter-chord. Increase in chord extension leads to an increase in the polar radius of gyration (Fig. 10), and hence, an increase in the polar moment of inertia.

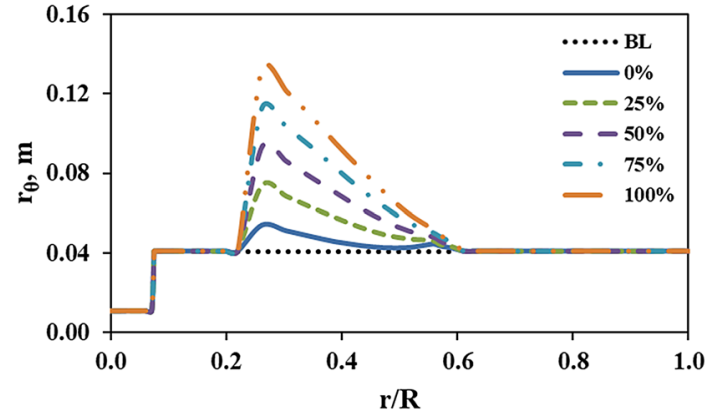

Fig. 10 Radial distribution of the polar radius of gyration

The structural data of the different surrogate models are used to perform structural dynamic analysis and obtain the Campbell diagram. Figure 11 compares the Campbell diagram of the baseline rotor blade with those of $0 \%$, $50 \%$ and $100 \%$ chord-extension cases. The diagrams show the first few natural modes until 10/rev. The fundamental flap and lag mode have hardly been affected. In line with the structural properties distribution, the higher flap frequencies have slightly reduced for the $0 \%$ chord extension compared to the baseline rotor but there is not much variation with increase in the chord-extension percentage. Flap-torsion coupling is seen close to the operating rotor speed for the chord-extension cases. However, it is not critical. This coupling is due to the offset of center of gravity from the shear center. The second lag mode has slightly 


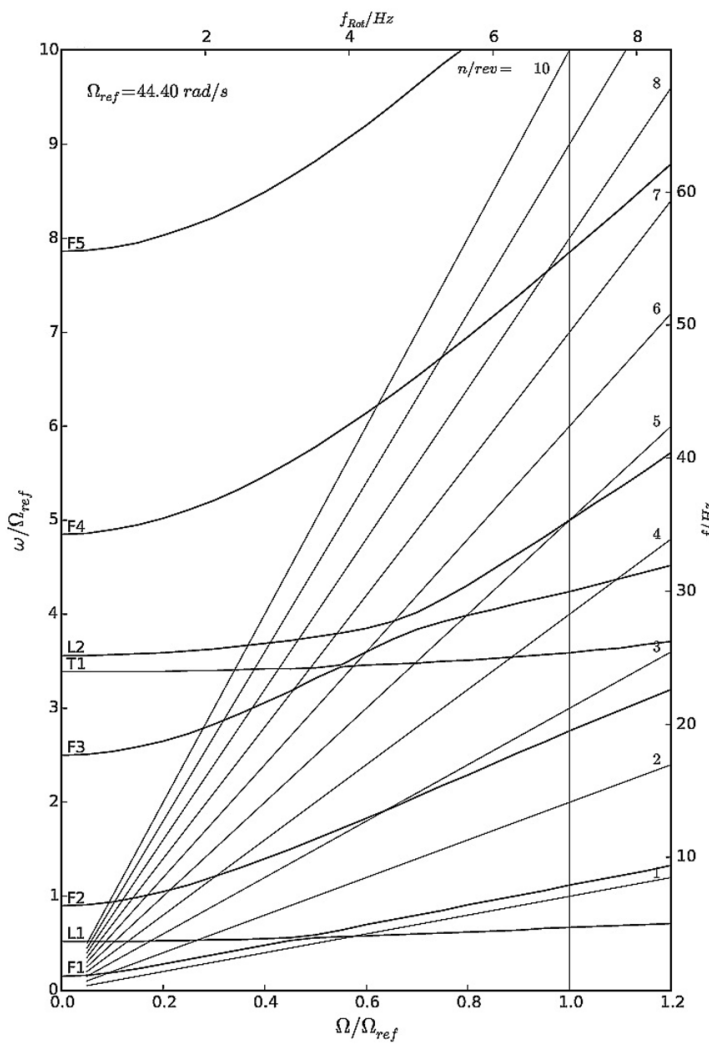

(a) Baseline rotor

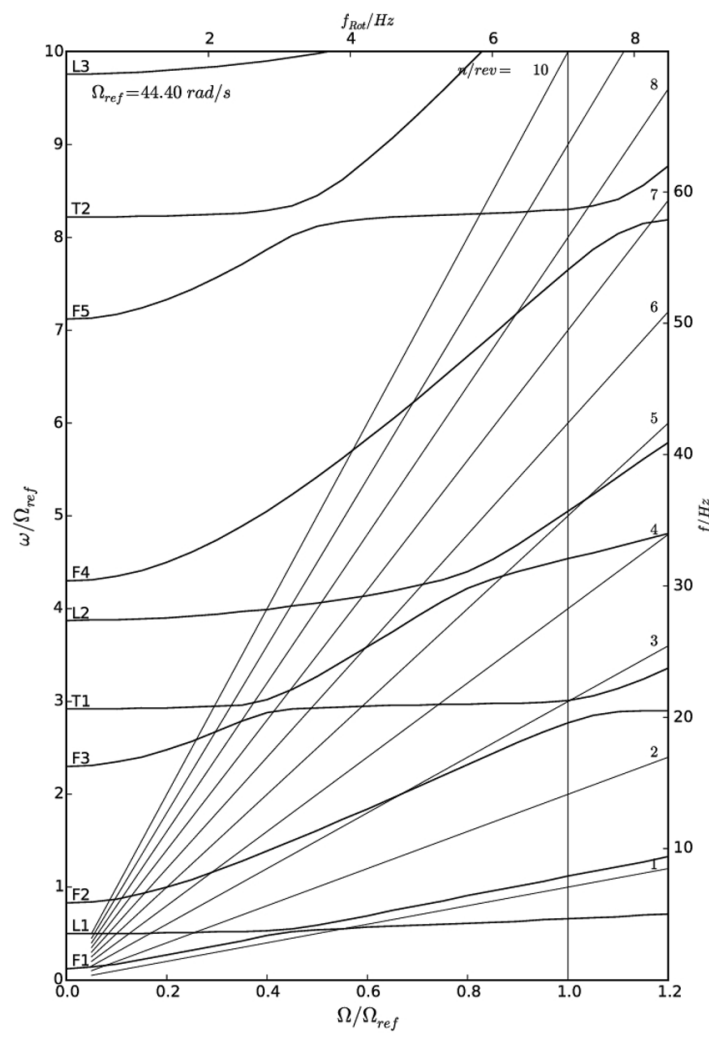

(c) $50 \%$ maximum chord-extension rotor

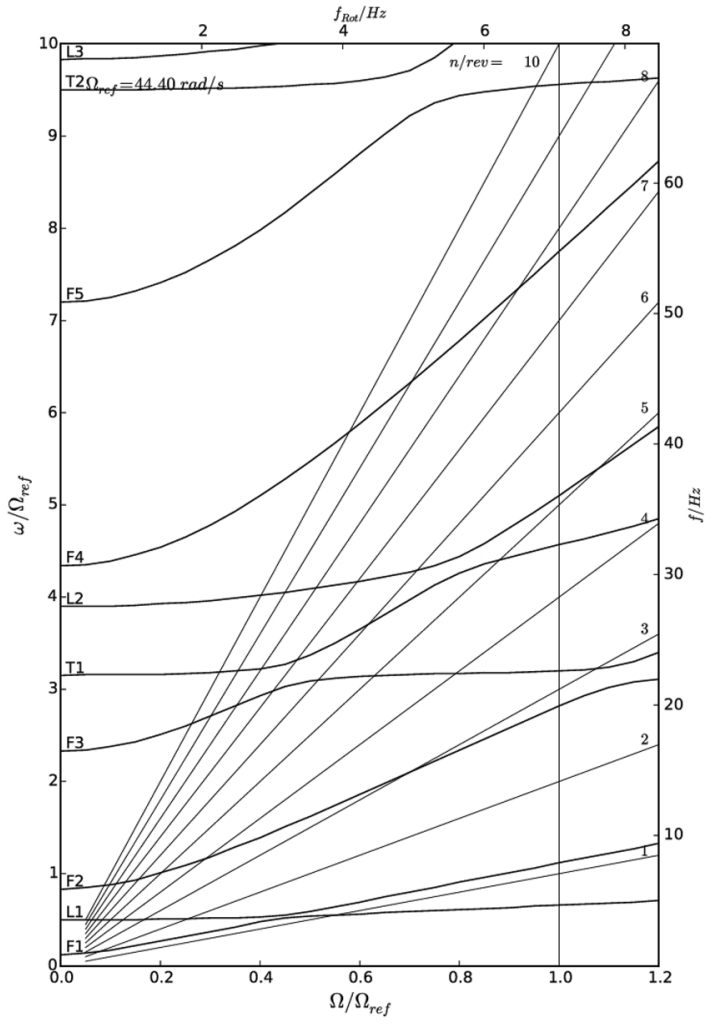

(b) $0 \%$ maximum chord-extension rotor

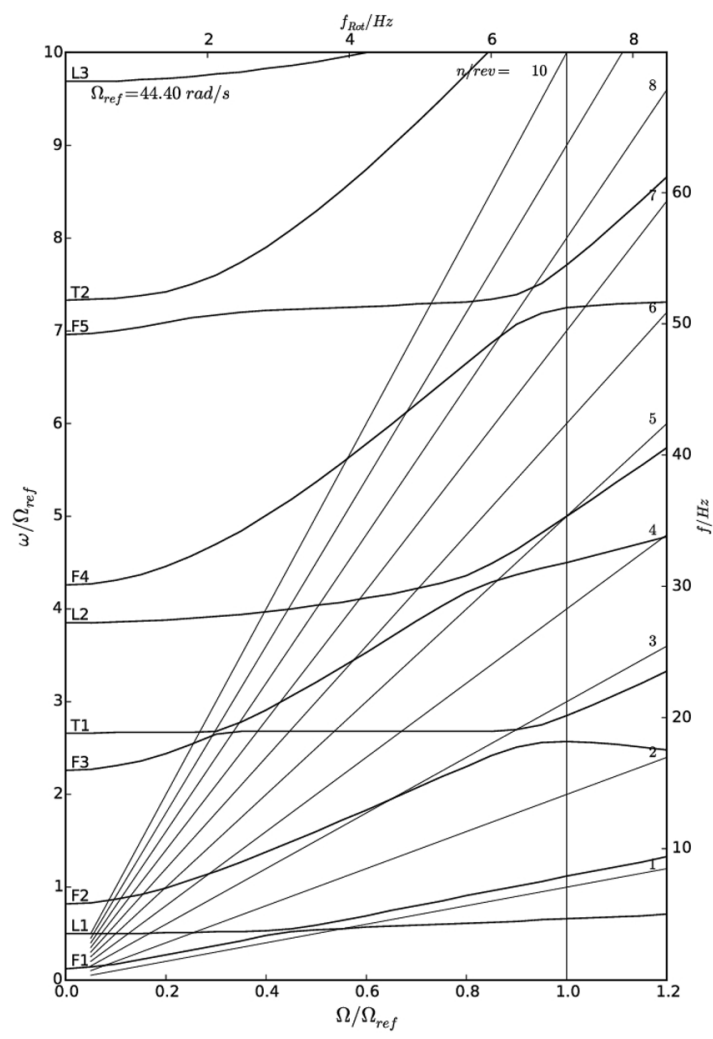

(b) $100 \%$ maximum chord-extension rotor

Fig. 11 Campbell diagrams for baseline and morphed rotors 
increased for the morphed rotors, while the third lag mode reduces to below 10/rev. The torsional frequencies are the most affected and have reduced considerably. The first torsion mode decreases with increasing chord extension. The second torsion mode reduces to below $10 / \mathrm{rev}$ for the morphed rotor. This reduction in torsional frequencies is, mostly, due to the increasing offset of the center of gravity from the shear center as the maximum chord extension is increased.

\subsection{Trim analysis}

Isolated rotor trim analysis with the fuselage-rotor inflow interference model included is then performed on the morphed rotor cases and their power requirements are compared with those of the baseline rotor. The baseline rotor geometrical and operating parameters are given in Table 1 in the Trim analysis is carried out for hover for up to a baseline

Table 1 Baseline rotor parameters

\begin{tabular}{llll}
\hline Description & Symbol & Value & Unit \\
\hline Radius & $R$ & 4.912 & $\mathrm{~m}$ \\
Angular velocity & $\Omega$ & 44.4 & $\mathrm{rad} / \mathrm{s}$ \\
Blade chord & $C$ & 0.27 & $\mathrm{~m}$ \\
Number of blades & $N_{\mathrm{b}}$ & 4 & - \\
Rotor solidity & $\sigma$ & 0.07 & - \\
Precone angle (pos. upward) & $\beta_{0}$ & 2.5 & $\circ$ \\
Pitch-flap coupling & $\Delta_{3}$ & 0 & $\circ$ \\
Radius of blade attachment main bolt & $r_{\mathrm{att}}$ & 0.372 & $\mathrm{~m}$ \\
Root cutout & $r_{\mathrm{c}}$ & 1.1 & $\mathrm{~m}$ \\
Linear twist of airfoiled section & $\Theta_{\mathrm{tw}}$ & -8 & $\circ / \mathrm{R}$ \\
Effective blade mass & $m_{\mathrm{b}}$ & 24.2 & $\mathrm{~kg}$ \\
Lock number (sea level) & $\gamma$ & 8.1 & - \\
Fundamental flap frequency & $\omega_{\beta}$ & 1.117 & - \\
Fundamental lag frequency & $\omega_{\zeta}$ & 0.666 & - \\
Fundamental torsion frequency & $\omega_{\theta}$ & 3.59 & - \\
\hline
\end{tabular}

blade loading $\left(C_{\mathrm{T}} / \sigma_{\mathrm{BL}}\right)$ of 0.16 and for forward flight velocities from 0 to $70 \mathrm{~m} / \mathrm{s}(\mu=0.32)$. The target hub moments are taken to be zero. Both chord extension and chord-extension-deflection are considered.

\subsection{Variation of blade loading at hover}

Figure 12a shows the figure of merit variation with baseline blade loading for various chord-extension cases. The design blade loading for the baseline Bo105 rotor is $C_{\mathrm{T}} / \sigma_{\mathrm{BL}}=0.0714$. It is clearly seen that the figure of merit (FM) increases with increase in chord extension. The FM for the baseline rotor at design thrust is 0.65 . For the same thrust, the FM for $100 \%$ chord extension is 0.7 representing an increase of 5 counts. The maximum FM of 0.73 is achieved for $100 \%$ chord extension for $C_{\mathrm{T}} / \sigma_{\mathrm{BL}}=0.1$. Figure $12 \mathrm{~b}$ shows the collective angle variation with blade loading for baseline and chordextended rotors. It can be seen that for a particular thrust, the collective angle requirement increases with increase in the chord extension. For $C_{\mathrm{T}} / \sigma_{\mathrm{BL}}=0.0714$, the required collective angle is $7.7^{\circ}$, while for $100 \%$ chord-extension case, the required collective angle increases by $3.6^{\circ}-11.3^{\circ}$. Similarly, at $C_{\mathrm{T}} / \sigma_{\mathrm{BL}}=0.16$, the required collective angle increases to $17.6^{\circ}$ for the $100 \%$ chord-extension case from $13^{\circ}$ for the baseline rotor. The increase in the collective angle requirement is caused by a decrease in the tip elastic twist of the blade as can be seen from Fig. 13 which shows the elastic twist for the different blades at $C_{\mathrm{T}} / \sigma_{\mathrm{BL}}=0.16$. Elastic twist which was

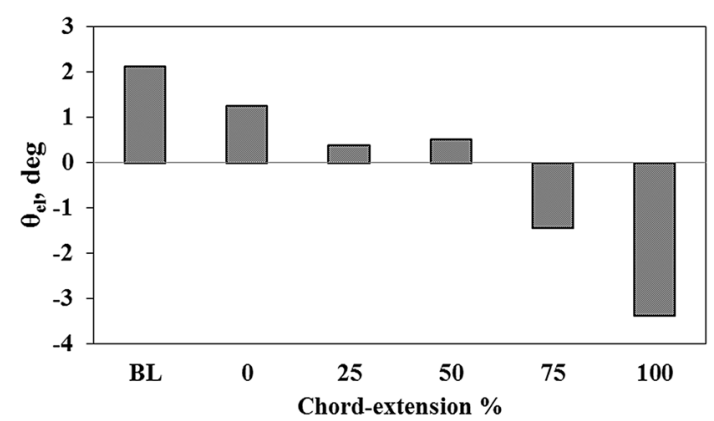

Fig. 13 Elastic torsion at $C_{\mathrm{T}} / \sigma_{\mathrm{BL}}=0.16$
Fig. 12 Figure of merit variation with blade loading for baseline and chord-extension rotors

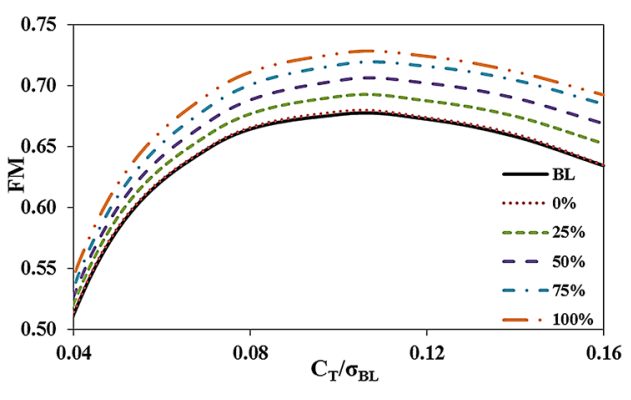

(a) FM variation with blade loading

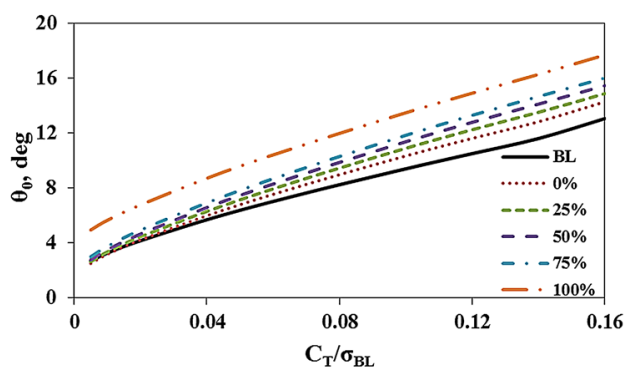

(b) Collective angle variation with blade loading 
nose-up for the baseline rotor decreases in magnitude and turns negative (nose-down) as chord extension increases. Correspondingly, the near root $(r=0.0757 R)$ torsional moment at this blade loading changes considerably from $42.9 \mathrm{Nm}$ for the baseline blade to $-216.16 \mathrm{Nm}$ (nose-down) for the $100 \%$ chord-extension case.

The reduction in required power, shown in Fig. 12a, can be understood by comparing the angle of attack distribution of the baseline rotor with that of the chord-extension rotors. Figure 14 shows the radial distribution of the angle of attack of the baseline rotor and $100 \%$ chord-extension rotor at the $90^{\circ}$ azimuth for $C_{\mathrm{T}} / \sigma_{\mathrm{BL}}=0.16$. Note that the curve for $15^{\circ}$ deflection of $100 \%$ chord extension is also shown but this maybe ignored for now. For the $100 \%$ chord-extension case, the sections from $r=0.35 R$ till $r=0.95 R$ have lesser angles of attack than those for the baseline case. On an average, the reduction is about $1.2^{\circ}$. This reduces the profile drag of a rather large part of the rotor blade for the $100 \%$ chord-extension rotor and hence, reduces the overall required power.

Next, the effect of chord-extension-deflection on power required is studied. Figure $15 \mathrm{a}$, b shows the power required plots for $C_{\mathrm{T}} / \sigma_{\mathrm{BL}}=0.0714$ and $C_{\mathrm{T}} / \sigma_{\mathrm{BL}}=0.16$, respectively. From Fig. 15a, there appears to be a decreasing trend for required rotor power with increase in chord deflection. The trend is more observable in higher chord extensions.

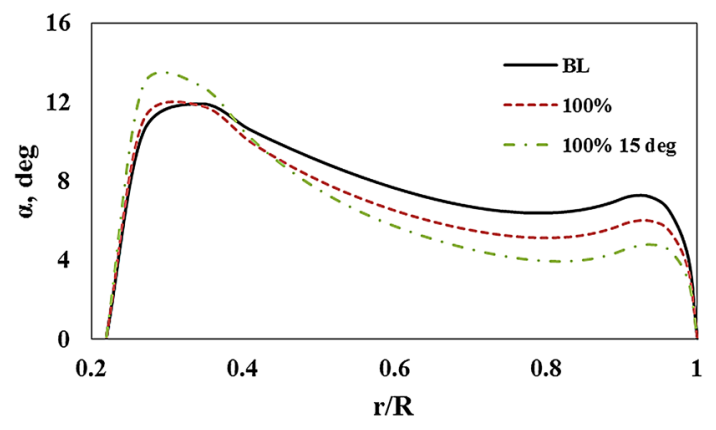

Fig. 14 Radial distribution of $\alpha$ for $C_{\mathrm{T}} / \sigma_{\mathrm{BL}}=0.16$

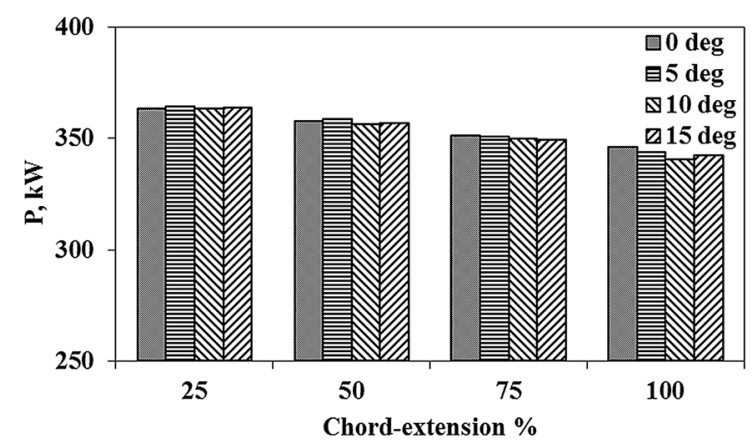

(a) $\mathrm{C}_{\mathrm{T}} / \boldsymbol{\sigma}_{\mathrm{BL}}=\mathbf{0 . 0 7 1 4}$
However, this reduction is small at the nominal blade loading. For the $100 \%$ chord-extension case, the difference in required power between the $0^{\circ}$ deflection and the $15^{\circ}$ deflection is only about $20 \mathrm{~kW}$. Figure $15 \mathrm{~b}$ shows the decreasing power trend clearly for all chord extensions. For the $100 \%$ chord-extension case, the difference in required power between the $0^{\circ}$ deflection and the $15^{\circ}$ deflection is about $90 \mathrm{~kW}$. Referring to the angle of attack distribution in Fig. 14, it can be seen that for the $100 \%$ chord-extension rotor with $15^{\circ}$ deflection, the sections from $r=0.40 R$ till $r=0.95 R$ have, on an average, a reduction of about $2.4^{\circ}$ in the angle of attack compared to the baseline case. This reduces the overall profile drag of the rotor blade for the $15^{\circ}$ chord-deflected rotor and thus, reduces the required power also. It may be noted from the airfoil polars in Fig. 5 that for positive angles of attack, the chord-deflection airfoils have higher lift than the undeflected airfoils or the baseline airfoil at the same angle of attack. Hence the required thrust can be met at lower angles of attack for the chord-deflection rotors compared to the rotor with no chord deflection. Figure 16a, b shows the collective angle requirement for $C_{\mathrm{T}} / \sigma_{\mathrm{BL}}=0.0714$ and $C_{\mathrm{T}} / \sigma_{\mathrm{BL}}=0.16$, respectively. There is a clear trend of collective angle requirement increasing with increase in the chord-deflection angle. From both the figures, a $7^{\circ}$ increase in the collective angle can be seen for the $100 \%$ chord-extension between $0^{\circ}$ and $15^{\circ}$ deflection.

Thus, for a $15^{\circ}$ chord deflection, the collective angle input exceeds the limits of the possible range of pilot input for this class of vehicle rendering it impractical. The increase in collective angle requirement with chord deflection is caused by an increase in nose-down tip elastic twist. Figure 17 shows this trend for the $100 \%$ chord-extension case at $C_{\mathrm{T}} / \sigma_{\mathrm{BL}}=0.16$. The nose-down tip elastic twist for the $15^{\circ}$ chord-deflection case is about $8.5^{\circ}$ more than that for the $0^{\circ}$ chord-deflection case. The root torsional moment $(r=0.0757 R)$ almost triples from $-216.16 \mathrm{Nm}$ (nose-down) for the $0^{\circ}$ chord-deflection case to $-597.9 \mathrm{Nm}$ (nose-down)

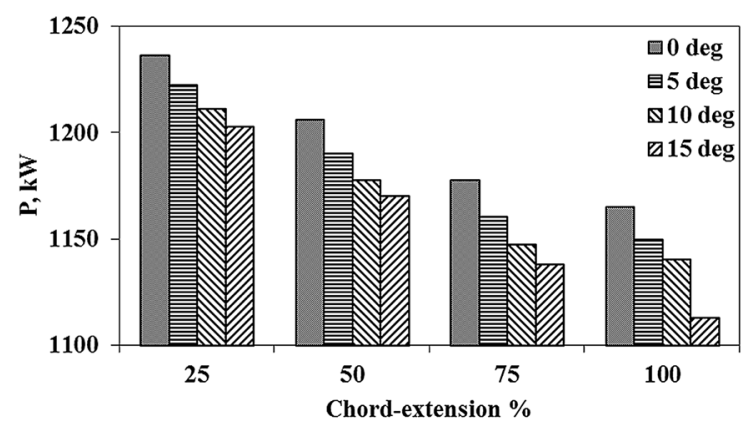

(b) $\mathrm{C}_{\mathrm{T}} / \sigma_{\mathrm{BL}}=\mathbf{0 . 1 6}$

Fig. 15 Required power variation with chord extension and chord deflection 


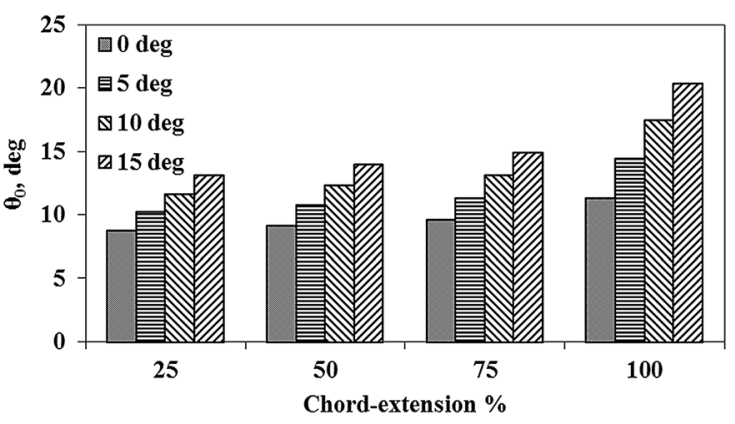

(a) $\mathrm{C}_{\mathrm{T}} / \sigma_{\mathrm{BL}}=0.0714$

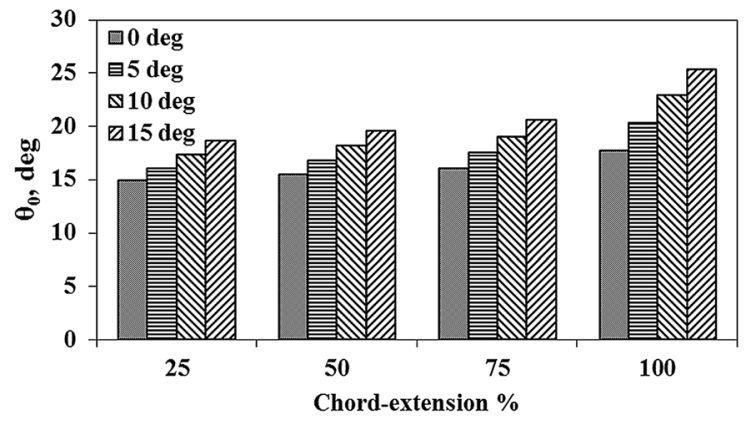

(b) $\mathrm{C}_{\mathrm{T}} / \boldsymbol{\sigma}_{\mathrm{BL}}=\mathbf{0 . 1 6}$

Fig. 16 Collective angle variation with chord extension and chord deflection

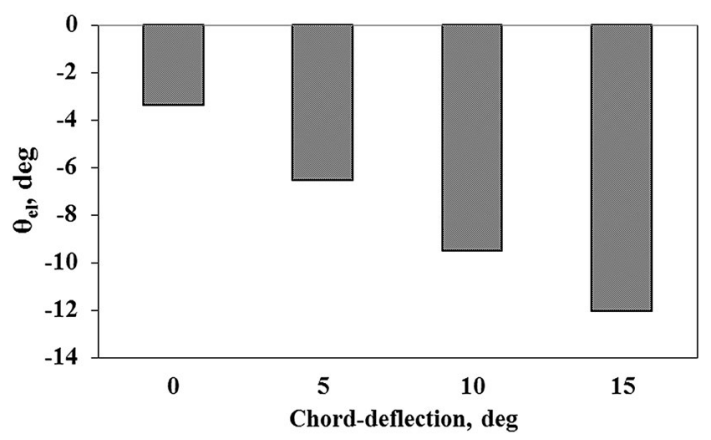

Fig. 17 Tip elastic twist variation with chord deflection for $100 \%$ chord extension at $C_{\mathrm{T}} / \sigma_{\mathrm{BL}}=0.16$

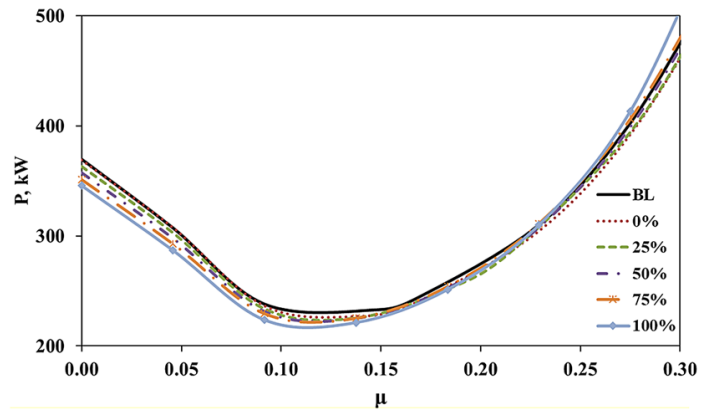

Fig. 18 Rotor required power variation with advance ratio for different maximum chord extensions, $C_{\mathrm{T}} / \sigma_{\mathrm{BL}}=0.0714$

for the $15^{\circ}$ chord-deflection case, tremendously increasing the stress at the root and in the pitch-link.

\subsection{Variation of advance ratio at $C_{\mathrm{T}} / \sigma_{\mathrm{BL}}=\mathbf{0 . 0 7 1 4}$}

Figure 18 shows the variation of rotor required power with advance ratio for the baseline rotor and rotors with varying chord extension. It is seen from the plot that the required

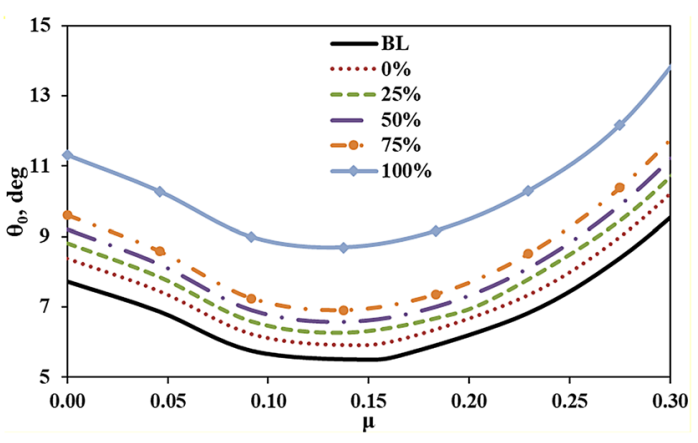

Fig. 19 Rotor collective angle input variation with advance ratio for different maximum chord extensions, $C_{\mathrm{T}} / \sigma_{\mathrm{BL}}=0.0714$

power reduces with increase in chord extension, especially at lower velocities. At hover, there is a drop of about $25 \mathrm{~kW}$ for the $100 \%$ chord-extension case relative to the baseline rotor. At $\mu=0.1$, this drop reduces to $14 \mathrm{~kW}$. At higher velocities, the chord-extended rotors give mixed results for required power when compared to the baseline rotor. The $0 \%$ chordextension rotor requires less power than the baseline rotor, while the $100 \%$ chord-extension rotor requires more power.

Figure 19 reveals that the rotor collective angle input increases for the morphed rotor compared to the baseline rotor. For example, there is a uniform increase of close to $3.5^{\circ}$ for the $100 \%$ chord-extension case over the baseline rotor. There are also slight differences in the cyclic angles requirement between the different rotors but these plots are not shown here. The increase in the collective angle requirement can be understood from Fig. 20 which shows the rotor blade tip mean elastic twist angle variation at hover, low and high advance ratios. An increase in the mean elastic twist is seen for the chord-extended rotors over the baseline rotor. There is an increase of about $3.8^{\circ}$ in the nose-down mean elastic twist from the baseline case to the $100 \%$ chord-extension case at each advance ratio. The reason for the increase in blade (nose-down) elastic twist is mainly the increased offset of the cg of the morphed section from the 


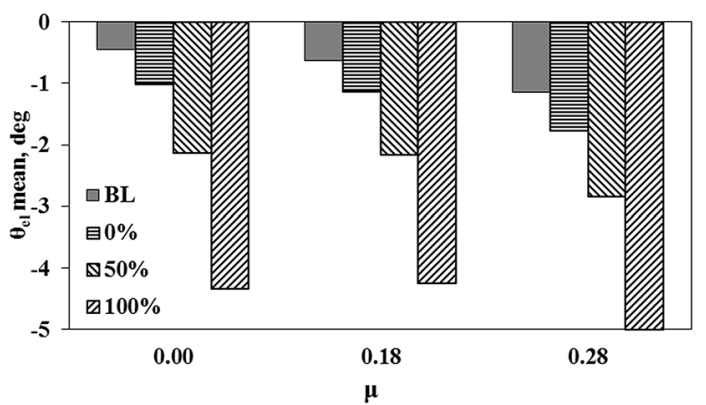

Fig. 20 Tip elastic twist variation with advance ratio, $C_{\mathrm{T}} / \sigma_{\mathrm{BL}}=0.0714$

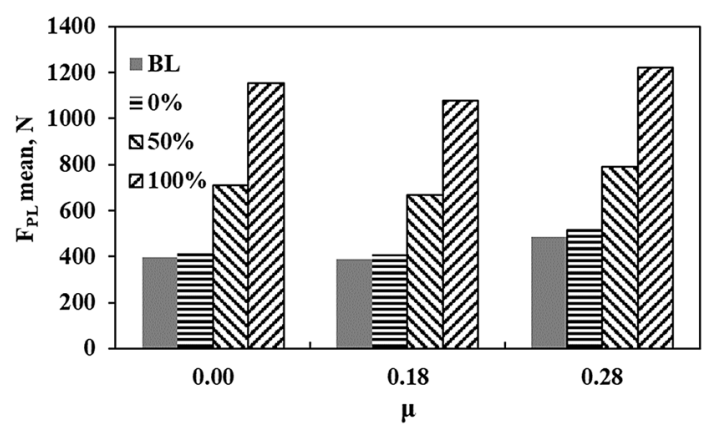

Fig. 21 Pitch-link mean load variation with advance ratio, $C_{\mathrm{T}} / \sigma_{\mathrm{BL}}=0.0714$

shear center (larger radius of gyration). The increased negative elastic twist for the chord-extension rotors is also reflected in the large nose-down torsional moments (near the root) which result in large pitch-link loads, as shown in Fig. 21. There is a significant increase of close to $800 \mathrm{~N}$ in the pitch-link mean loads for all advance ratios. The first harmonic of the pitchlink load (Fig. 22) has also registered a large increase for high forward speed. This indicates a significant increase in the peakto-peak loads, thus countering any benefit in the power saved.

Figure 23 shows the effects of chord deflection. Figure $23 \mathrm{a}$ gives the variation of the power requirement with advance ratio for a $50 \%$ chord-extended blade at various chord deflections. It is observed that the power requirement increases with chord deflection in forward flight. There is a maximum increase of about $50 \mathrm{~kW}$ at $\mu=0.23$. This is because for most regions of the rotor disc, the angle of attack for the chord-deflected blade is close to or higher than that for the baseline blade resulting in higher profile drag for the chord-deflected airfoil. The collective angle input also increases substantially (Fig. 23b) with increase in chord deflection. There is an average increase of about $6^{\circ}$ from $0^{\circ}$ chord deflection to $15^{\circ}$ chord deflection across advance ratios. The increase in collective angle is because of the increase in nose-down tip elastic twist. For instance, at $\mu=0.18$, the nose-down tip elastic twist increases from $-2.16^{\circ}$ for the $0^{\circ}$ chord-deflection case to $-8.86^{\circ}$ for the $15^{\circ}$ chord-deflection case. Similarly, the nose-down torsional moment near the root $(r=0.0757 \mathrm{R})$ increases from $-85.5 \mathrm{Nm}$ for the $0^{\circ}$ chord-deflection case to -364.85 for the $15^{\circ}$ chord-deflection case. The large torsional moment near the root add severe stress to the pitch-link.

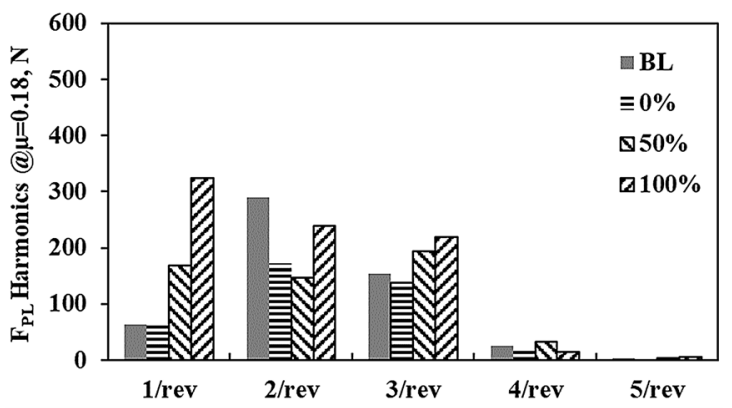

(a)

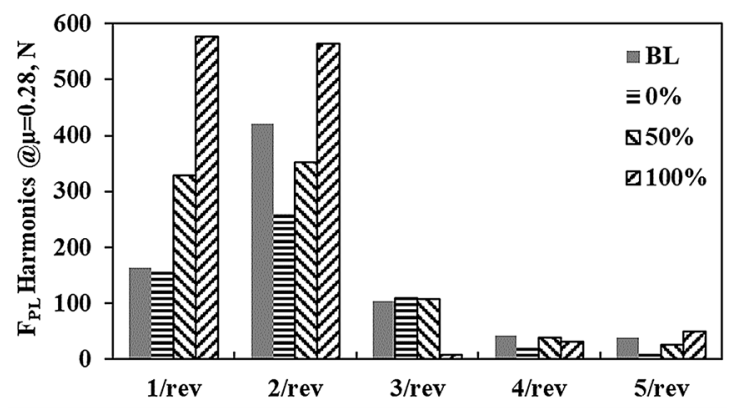

(b)

Fig. 22 Pitch-link load harmonics in forward flight at $\mathbf{a} \mu=0.18$ and $\mathbf{b} \mu=0.28$ 


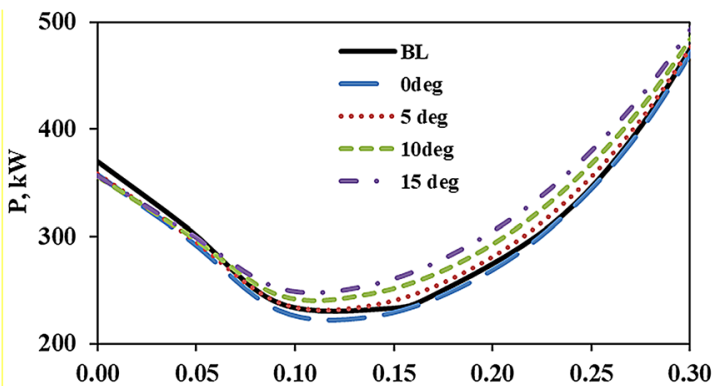

(a) $\mu$

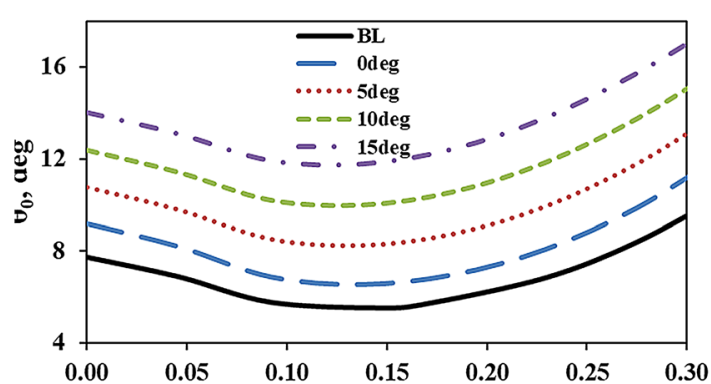

(b) $\mu$

Fig. 23 Rotor required power (a) and collective angle (b) variation with velocity for 50\% maximum chord extension at various chord deflections, $C_{\mathrm{T}} / \sigma_{\mathrm{BL}}=0.0714$

\section{Concluding remarks}

A new concept of chord-morphing called the linearly variable chord extension was investigated in this work for its effectiveness in improving the rotor efficiency. Rotors with maximum chord extension up to $100 \%$ and chord deflection up to $15^{\circ}$ were analyzed. This concept was found to be promising in improving efficiency. The important findings are:

1. Chord extension causes aft movement of the center of gravity and increase in its offset from the shear center (increase in polar radius of gyration). This introduces flap-torsion coupling.

2. The reduced torsional stiffness in the morphed region by design optimization reduces the torsional frequencies of the rotor blade.

3. The reduced torsional stiffness and the increase in the polar radius of gyration cause an increase in the nose-down elastic torsion for the morphed rotor. This increases the collective angle requirement

4. Root torsional moments and hence, the pitch-link loads increase substantially due to chord-extension and chordextension-deflection.

5. In hover and low forward velocities, the overall rotor power requirement is reduced for chord-extension rotors. This is due to the reduction in angles of attack across the rotor blade of the chord-extension rotors as compared to the baseline rotor.

6. Chord extension was found to be not so beneficial at high forward velocities due to negligible power savings and large structural loads.

7. Chord deflection is found to be favorable in hover for reducing rotor power requirement, especially at higher blade loadings. But for larger chord deflections, the collective angle requirement may exceed the possible limits.

8. For forward velocities, chord deflection was found to increase rotor power requirement and hence is not beneficial.
Acknowledgements This project has received funding from the European Union's Horizon 2020 research and innovation program under Grant Agreement no. 723491.

Funding Open Access funding enabled and organized by Projekt DEAL.

Open Access This article is licensed under a Creative Commons Attribution 4.0 International License, which permits use, sharing, adaptation, distribution and reproduction in any medium or format, as long as you give appropriate credit to the original author(s) and the source, provide a link to the Creative Commons licence, and indicate if changes were made. The images or other third party material in this article are included in the article's Creative Commons licence, unless indicated otherwise in a credit line to the material. If material is not included in the article's Creative Commons licence and your intended use is not permitted by statutory regulation or exceeds the permitted use, you will need to obtain permission directly from the copyright holder. To view a copy of this licence, visit http://creativecommons.org/licenses/by/4.0/.

\section{References}

1. Kang, H., Saberi, H., Gandhi, F.: Dynamic blade shape for improved helicopter rotor performance. J. Am. Helicopt. Soc. 55(3), 32008 (2010)

2. Khoshlahjeh, M., Gandhi, F.: Extendable chord rotors for helicopter envelope expansion and performance improvement. J. Am. Helicopt. Soc. 59(1), 1-10 (2014)

3. Barbarino, S., Gandhi, F., Webster, S.D.: Design of extendable chord sections for morphing helicopter rotor blades. In: ASME 2010 Conference on Smart Materials, Adaptive Structures and Intelligent Systems, American Society of Mechanical Engineers, pp. 323-336 (2010)

4. Han, D., Yang, K., Barakos, G.N.: Extendable chord for improved helicopter rotor performance. Aerosp. Sci. Technol. 80, 445-451 (2018)

5. Rauleder, J., van der Wall, B. G., Abdelmoula, A., Komp, D., Kumar, S., Ondra, V., Titurus, B., and Woods, B.K.: Aerodynamic performance of morphing blades and rotor systems. In: AHS 74th Annual forum \& Technology Display, Phoenix, Az (2018)

6. Gessow, A., Myers, G.C.: Aerodynamics of the Helicopter, 3rd edn. Frederick Ungar Publishing Co, New York (1967) 
7. Leiss, U.: A consistent mathematical model to simulate steady and unsteady rotor-blade aerodynamics. In: 10th European Rotorcraft Forum, The Hague, Netherlands (1984)

8. van der Wall, B.G.: An Analytical model of unsteady profile aerodynamics and its application to a rotor simulation program. In: 15th European Rotorcraft Forum, Amsterdam, Netherlands (1989)

9. Houbolt, J.C., Brooks, G.W.: Differential equations of motion for combined flapwise bending, chordwise bending, and torsion of twisted nonuniform rotor blades. In: NACA TN 3905 (1957)
10. Mangler, K.W., Squire, H.B.: The induced velocity field of a rotor. In: Aeronautical Research Council, RM No 2642 (1953)

11. Bo105: Configuration Data. WP-10 report GARTEUR HC AG 16 (2006)

Publisher's Note Springer Nature remains neutral with regard to jurisdictional claims in published maps and institutional affiliations. 